\title{
REVISED VERSION: \\ INFLUENCE OF REACTOR PRESSURE ON THE PRIMARY JET BREAKUP OF HIGH-VISCOSITY FUELS: BASIC RESEARCH FOR SIMULATION-ASSISTED DESIGN OF LOW-GRADE FUEL BURNER
}

\author{
Thomas Müller* \\ Kathrin Kadel \\ Peter Habisreuther \\ Dimosthenis Trimis \\ Nikolaos Zarzalis \\ Engler-Bunter-Institute \\ Karlsruhe Institute of Technology (KIT) \\ Karlsruhe, Germany
}

\author{
Alexander Sänger \\ Tobias Jakobs \\ Thomas Kolb \\ Institute for Technical Chemistry \\ Karlsruhe Institute of Technology \\ Karlsruhe, Germany
}

\begin{abstract}
Detail investigations on the primary breakup of highviscosity liquids using external-mixing twin-fluid nozzles at increased system pressure are scarce. Therefore, the research work of the present study is focused on the investigation of pressure influence (1 - 11 bar (abs)) on the primary breakup by numerical simulation based on a previously studied nozzle [Müller et al., ASME Turbo Expo 2016, GT2016-56371]. The pressure influence was investigated for two liquids applying a wide range of viscosities (100 $\mathrm{mPa}$ s; $400 \mathrm{mPa}$ s) and two atomizing air velocities $(58 \mathrm{~m} / \mathrm{s} ; 74 \mathrm{~m} / \mathrm{s})$. To describe the disintegration process of the fluids, characteristic features like liquid jet morphology, breakup length and breakup frequency were evaluated.

The primary breakup was investigated using the open source CFD software OpenFOAM. To gather the morphology of the primary breakup and the flow field characteristics compressible large eddy simulations (LES) were performed and the movement of the gas-liquid interface was captured by means of the Volume of Fluid-Method (VOF).

The conducted simulations showed good agreement with experimental results with respect to the characteristic features (e.g. morphology and breakup length) and revealed a decrease of the
\end{abstract}

breakup length with increasing ambient pressure for a constant liquid mass flow and atomizing air velocity. Moreover, those findings will contribute to a better understanding of the physics of the breakup of high-viscosity liquid jets and as well to create an experimentally validated CFD based tool for future burner development and optimization.

\section{NOMENCLATURE}

\section{Latin letters}

\begin{tabular}{|c|c|c|c|}
\hline$A$ & Area & $C$ & Fitting parameter \\
\hline$D$ & Diameter & $\mathrm{F}_{\sigma}$ & $\begin{array}{l}\text { Volumetric surface } \\
\text { tension force }\end{array}$ \\
\hline$L$ & Length & $P$ & Scalar pressure \\
\hline$S_{f}$ & $\begin{array}{l}\text { Outward-pointing } \\
\text { vector of the cell face }\end{array}$ & $T$ & Temperature \\
\hline$U$ & Mean velocity & $\mathrm{U}$ & Velocity vector \\
\hline$a$ & Fitting parameter & $c_{v}$ & $\begin{array}{l}\text { Specific volumetric heat } \\
\text { capacity }\end{array}$ \\
\hline
\end{tabular}




$\begin{array}{llll}e & \text { Total energy } & f & \text { Frequency } \\ \mathrm{g} & \begin{array}{l}\text { Gravitational } \\ \text { acceleration }\end{array} & \dot{m} & \text { Mass flow } \\ \dot{q} & \text { Conductive heat flux } & s & \text { Web thickness } \\ t & \text { Time } & x, y, z & \text { Directions in space }\end{array}$

\section{Greek letters}

$\begin{array}{llll}\alpha & \text { Volume fraction } & \kappa & \text { Curvature of the surface } \\ \mu & \text { Dynamic viscosity } & \phi & \text { Arbitrary variable } \\ \psi & \text { Compressibility } & \rho & \text { Density } \\ \sigma & \text { Surface tension } & \tau & \text { Viscous stress tensor }\end{array}$

\section{Non-dimensional parameters}

$\begin{array}{ll}R e & \text { Reynolds number } \\ O h & \text { Ohnesorge number }\end{array}$

$\begin{array}{ll}\text { We } & \text { Weber number } \\ M & \text { Momentum ratio }\end{array}$

GLR Gas-liquid ratio

\section{Subscripts}

$\begin{array}{llll}b & \text { Breakup } & c & \text { Compression } \\ g & \text { Gas } & f & \text { Based on the cell face } \\ h & \text { Hydraulic } & l & \text { Liquid }\end{array}$

\section{MOTIVATION AND INTRODUCTION}

Low quality fuels such as pyrolysis oils and coal-waterslurries (CWS) are increasingly used due to the shortage of conventional fuels and the necessity to reduce $\mathrm{CO}_{2}$-emissions. In terms of the applicability of such liquids, the complex atomisation behaviour is most challenging, as their physical properties like viscosity and surface tension vary in a wide range.

Utilisation of such low-grade fossil or biogenic liquid fuels is possible by conversion to synthesis gas (main components: $\mathrm{CO}$ $\& \mathrm{H}_{2}$ ). For example, via high pressure entrained flow gasification (EFG) which offers a wide variety of further applications for the syngas [1]: (I) synthesis of methane (SNG), (II) production of high quality speciality chemicals via a synthesis (CtL; BtL) or (III) firing in an IGCC power plant.

Due to the afore mentioned fuel properties gas assisted burner nozzles areare used mainly, because they allow to apply low liquid velocities and therefore reasonable pressure drops despite of the high viscosities uf such liquids. As the spray properties such as droplet size distributions, spray angle and the flow field generated by the the burner nozzle are of major importance for the production of a high quality syngas [2], a good atomisation behaviour of the nozzle is essential.

With regard to the specific operating conditions of the EFG the atomisation is confronted with several challenges: (I) high viscosity (up to $1000 \mathrm{mPas}$ ), (II) complex rheological behaviour, (III) operation at elevated reactor pressure (up to 80 bar) and (IV) operation in oxygen-blown mode. In the oxygen-blown mode the atomisation agent also serves as gasification agent to increase the overall efficiency of the process, which limits the amount of atomization agent, as the amount of gasification agent is limited by the stoichiometry of the reaction. Since the spray quality decreases with the amount of available atomisation agent, a thorough understanding of the atomisation process of high-viscosity fuels is needed.

The atomisation characteristics of external mixing twin-fluid nozzles can be described by: The liquid (Eqn. (1) and gas Reynolds numbers (Eqn. (4), the aerodynamic Weber number (Eqn. (2)], the Ohnesorge number (Eqn. (5)], the momentum flux ratio (Eqn. (3) and the gas-liquid ratio (Eqn. (6).

$$
\begin{array}{lll}
R e_{l}=\frac{\rho_{l} U_{l} D_{l}}{\mu_{l}} & \text { (1) } & R e_{g}=\frac{\rho_{g} U_{g} D_{h}}{\mu_{g}} \\
W e=\frac{\rho_{g} U_{r e l}^{2} D_{l}}{\sigma} & \text { (2) } & \text { Oh }=\frac{\mu_{l}}{\sqrt{\rho_{l} \sigma D_{l}}} \\
M=\frac{\rho_{g} U_{g}^{2}}{\rho_{l} U_{l}^{2}} & \text { (3) } & G L R=\frac{\dot{m}_{g}}{\dot{m}_{l}}
\end{array}
$$

Here, $U_{g}, U_{l}$ and $U_{r e l}$ denote the mean gas, mean liquid and mean relative gas/liquid velocity, respectively. $D_{h}$ is the hydraulic diameter, which is defined as twice the annular gap width of the gas channel.

Twin-fluid nozzles have been been thoroughly investigated in literature, but theses studies were mostly limited to atmospheric pressure and low-viscosity liquids: An overview of the experimental investigations is provided by [3]. For example, the breakup regimes, the liquid core lengths and the breakup frequencies of coaxial air-water jets were investigated by [4-8]. Moreover, liquid core lengths were also studied by [9, 11]. Additionally, the influence of reactor pressure upon the breakup of a water jet for pressures up to 21 bar was investigated by [2].

Numerical studies are mostly focused on the primary jet breakup due to the high computational costs and similarly limited to low-viscosity liquids: For example, the primary breakup of a water jet was studied by [15]. A general overview upon the modelling of primary atomisation is provided by [16].

In Fig. 1a the two dominating breakup regimes for highviscosity liquids are shown: membrane (left) and fiber type (right), with the former one prevailing at lower $G L R$ and/or higher viscosity.

In addition, two different jet destabilisation mechanism were detected in a previous study [17], as illustrated in Fig. 1b: A pulsating mode consisting of a longitudinal and axis-symmetric mode triggered by a Kelvin-Helmholtz instability (Fig. 1b(left)) and a flapping mode characterized by a deflection in radial direction shortly after the nozzle (Fig. 1b(right)). Moreover, a transition between both modes was detected for some operating con- 
ditions. Additionally, droplet size measurements showed [17], that the flapping instability mode results in a wider spray angle and smaller SMD than the pulsating mode for the same operating conditions.

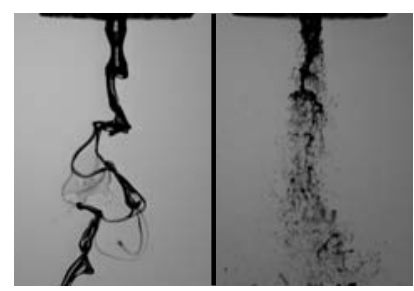

(a) BREAKUP REGIMES: MEMBRANE (LEFT) AND FIBER TYPE (RIGHT)[17]

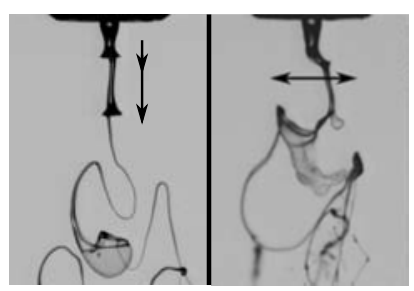

(b) INSTABLITY MODES: PULSATING (LEFT) AND FLAPPING (RIGHT) [17]

\section{FIGURE 1: MORPHOLOGY OF LIQUID JET BREAKUP}

Sänger et al. [18] studied the influence of reactor pressure upon the atomisation of high-viscosity liquids for constant relative velocities between gas and liquid. There, a decrease of the drop size was reported with increasing ambient pressure. Jampolski et al. [19] investigated the connection between stabilisation of suspension fuels and its impact upon the atomisation performance. In this context, a dependency of the spray angle as well as the droplet size upon the primary instability mode was also reported. Moreover, gasification experiments with an atmospheric lab-scale plant showed an impact of the atomisation quality upon the produced syngas quality. In this experiments an external mixing twin-fluid nozzle similar to the ones investigated here was used [2].

Apart from the experimental investigations, numerical simulations were conducted to study the primary breakup of highviscosity liquids $[20-22]$. The data obtained by the simulations was successfully validated with the experiments: For instance, the results showed good agreement with the measurements with regard to the breakup morphology and the mode of the primary instability as well as the breakup frequency and length.

The objective of this study is the investigation of the influence of reactor pressure upon the primary breakup process by numerical simulations.

\section{NUMERICAL FORMULATION}

The compressibleInterFoam-code of the open source $\mathrm{C}++$ libraries of OpenFOAM [23] (Version 2.4.0) is used in this study to conduct the two-phase flow simulations. It applies the Volume of Fluid-Method (VOF) by Hirt and Nichols [24] to capture the interface. The following section gives a short summary upon the modelling approach. For a more detailed description the reader is referred to previous publications [20,21].

\section{Governing equations}

The two-phase flow at hand can be described by the conservation equations of mass (Eqn. (7)), momentum (Eqn. (8)), energy (Eqn. (9)) and the continuity equation of the liquid mass (Eqn. (10)):

$\frac{\partial \rho}{\partial t}+\nabla \cdot(\rho \mathrm{U})=0$

$\frac{\partial(\rho \mathrm{U})}{\partial t}+\nabla \cdot(\rho \mathrm{UU})=-\nabla P+\nabla \cdot \tau+\rho \mathrm{g}+\mathrm{F}_{\sigma}$

$\frac{\partial(\rho e)}{\partial t}+\nabla \cdot(\rho e \mathrm{U})=-\nabla \cdot(P \mathrm{U})+\nabla \cdot(\tau \mathrm{U})-\nabla \dot{q}$

$\frac{\partial\left(\rho_{l} \alpha_{l}\right)}{\partial t}+\nabla \cdot\left(\rho_{l} \alpha_{l} \mathrm{U}_{l}\right)=0$

$\tau$ represents the viscous stress tensor and is defined as $\tau=$ $2 \mu\left(0.5\left[(\nabla \mathrm{U})+\left(\nabla \mathrm{U}^{\top}\right)\right]\right)$, while $e$ is total energy with $e=c_{v} T+$ $0.5|\mathrm{U}|^{2}$.

\section{Interface capturing}

Interface capturing is done by the application of the VOFmethod [24]. The method uses the advection equation of the liquid volume fraction $\alpha_{l}$ to capture the gas-liquid interface (see Eqn. (11), for the sake of better readability the liquid volume fraction is from here on denoted without subscript $\alpha_{l} \equiv \alpha$ ), from which the phase inside the cell is derived. Usually, the liquid is represented by $\alpha=1$ and the gas by $\alpha=0$. For detailed information as well as the derivation of Eqn. (11) from (7) and (10) the reader is referred to literature, e.g. [20].

$$
\begin{aligned}
\frac{\partial \alpha}{\partial t}+\nabla \cdot(\mathrm{U} \alpha)+\nabla & \cdot\left(\alpha(1-\alpha) \mathrm{U}_{c}\right) \\
& =\alpha(1-\alpha)\left(\frac{\psi_{g}}{\rho_{g}}-\frac{\psi_{l}}{\rho_{l}}\right) \frac{D P}{D t}+\alpha \nabla \cdot \mathrm{U}
\end{aligned}
$$


The transport of the liquid volume fraction is calculated based on the flow field of a hypothetical continuous fluid throughout the domain, whose physical properties are dependent on $\alpha$. Any arbitrary physical property $\phi$ such as density or viscosity are calculated by an average of the propiertes of gas $\phi_{g}$ and liquid $\phi_{l}$ weighted by the liquid volume fraction $\alpha$ according to [25]:

$\phi=\phi_{l} \alpha+\phi_{g}(1-\alpha)$

The volumetric surface tension force in Eqn. (8) is calculated with the CSF model proposed by Brackbill et al. [26]:

$\mathrm{F}_{\sigma}=\sigma \kappa(\alpha) \nabla \alpha, \quad$ with $\quad \kappa(\alpha)=-\nabla \cdot\left(\frac{\nabla \alpha_{f}}{\left|\nabla \alpha_{f}\right|} \cdot S_{f}\right)$

From Eqn. (13) it becomes apparent, that the calculation of the surface tension force is highly dependent upon a sharp resolution of the interface. To guarantee this, the numerical diffusion has to be limited, as otherwise the interface is spread over several cells. It is mostly influenced by grid resolution as well as the discretization scheme of the first divergence term in Eqn. (11).

To minimize the numerical diffusion an artificial interface compression velocity $\mathrm{U}_{c}$ is applied in the second divergence term in Eqn. (11) following the algebraic counter-gradient approach by Weller [27] and calculated as formulated by [25].

\section{Turbulence modelling}

As the proper prediction of the transient turbulent gas flow is decisive for the modelling of the atomisation process in twinfluid nozzles, an LES approach is chosen, based on spatial filtering of the flow field [29]. An algebraic Smagorinsky model [30] was used for the calculation of the unknown subgrid-scale stress tensor, which is further detailed in the work of Fureby [31].

A detailed reasoning for the choice of the subgrid-scale model as well as a comparison of the calculated flow field with experimental measurements is given in a previous publication [20].

\section{SETUP}

The upcoming section presents the experimental and numerical setup, amongst others: the test rig and the investigated twinfluid nozzle, the properties of model liquids and the atomisation agent as well as the numerical domain and the boundary conditions.

\section{Experimentally investigated atomizer nozzle}

The measurements for this work were conducted at the PAT test rig. A detailed description of this facility is given in [13].

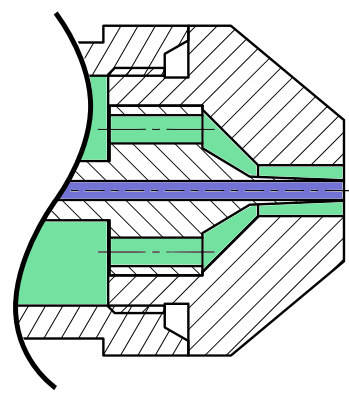

(a) SIDE VIEW

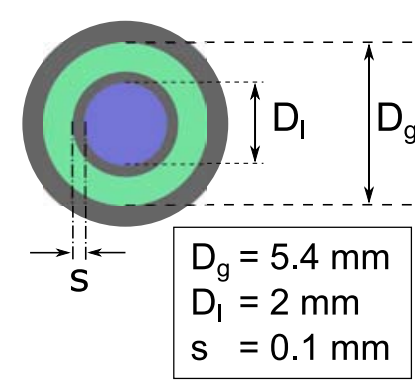

(b) FRONT VIEW
FIGURE 2: SCHEMATIC OF THE INVESTIGATED TWIN FLUID NOZZLE

Figure 2 despicts a schematic of the external mixing twinfluid nozzle, which was used in the experiments [18]. It is the same as the one used in [20,21]. Liquid is supplied through a central tube (blue), whereas the atomisation agent flows in the concentric annular duct (green). For more details, the reader is referred to [20].

\section{Numerical domain}

Figure 3 depicts a half-section of the numerical domain, which is cropped in the $\mathrm{x}$-direction approximately $50 \mathrm{~mm}$ after the nozzle exit for the sake of better visualisation. It is the same as the one used in previous publications [20,21].

The domain includes the region of the primary breakup as well as the internal of the nozzle. It is based on a structured grid composed of hexahedral cells starting from a central block. The central block has an edge length of $50 \mu \mathrm{m}$ and a cut of the mesh in the $\mathrm{x}$-y-plane (detail (I)) as well as in the y-z-plane (detail (II)) is shown in Fig. 3. For more details the reader is referred to [20,21].

\section{Boundary conditions and fluid properties}

The used boundary conditions are similar to the ones used in [20]: For the velocity field non-slip conditions at the walls, a zero-gradient condition at the ambience and a uniform velocity profile corresponding to the given mass flows at the inlets. The pressure was set to the given operating point at the ambience, apart from that a zero-gradient conditon was used.

The measured surface tension $\sigma$, the dynamic viscosity $\mu$ and the density $\rho$ of the model liquids are listed in Tab. 1. In addition, the density and viscosity of the air, that was used as 


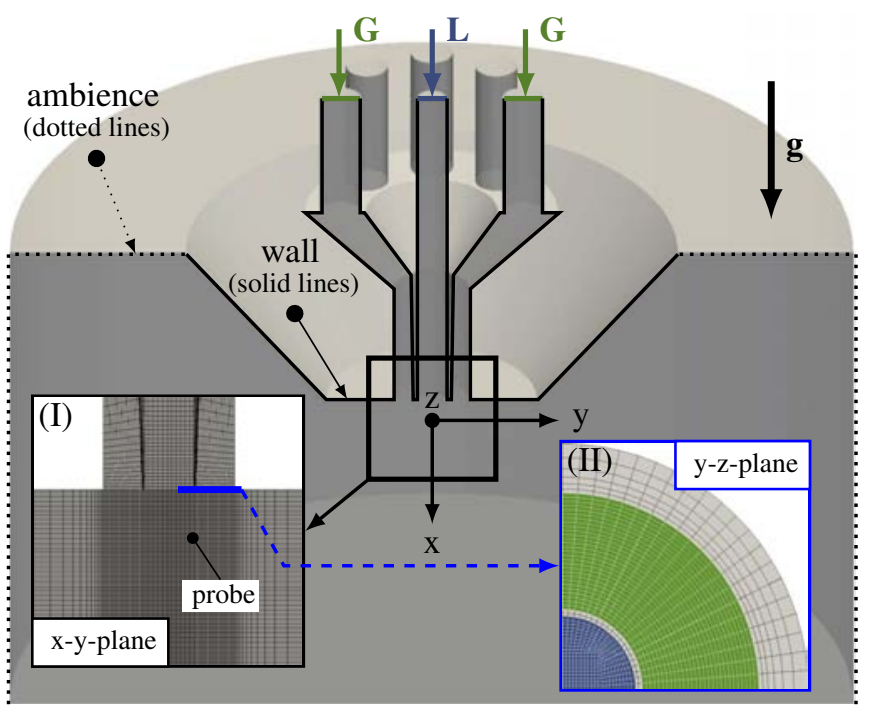

FIGURE 3: NUMERICAL DOMAIN OF THE TWO-PHASE SIMULATIONS

TABLE 1: PHYSICAL PROPERTIES OF THE FLUIDS

\begin{tabular}{lcccc}
\hline Fluid & $\begin{array}{c}\rho \\
\mathrm{kg} \mathrm{m}^{-3}\end{array}$ & $\begin{array}{c}\mu \\
\mathrm{mPas}\end{array}$ & $\begin{array}{c}\sigma \\
\mathrm{mNm}^{-1}\end{array}$ & $\begin{array}{c}\text { Oh } \\
-\end{array}$ \\
\hline A & 1223 & 100 & 64.8 & 0.2512 \\
B & 1248 & 400 & 64.1 & 1 \\
\hline Air (1 bar) & 1.205 & & & \\
Air (2 bar) & 2.378 & & & - \\
Air (7 bar) & 8.321 & 0.0182 & - & \\
Air (11 bar) & 13.077 & & & \\
\hline
\end{tabular}

atomisation agent, are listed. For detailed information, the reader is referred to [21].

\section{RESULTS}

An overview about the operating conditions of the conducted simulations is given in Tab. 2. The liquid mass flow was set to a constant value of $12 \mathrm{~kg} \mathrm{~h}^{-1}$ during all simulations, while the volumetric air flow was adapted according to the pressure, so that the nozzle exit velocity was constant. The acronyms for each case use the following system: The first letter distinguishes between fluid $\mathrm{A}$ and $\mathrm{B}$, the first number identifies the gas exit velocity with either 1 or 2 representing $58 \mathrm{~m} \mathrm{~s}^{-1}$ and $74 \mathrm{~m} \mathrm{~s}^{-1}$, respectively. The last digit then specifies the individual case.

Each of the simulation represents a physical time span of
TABLE 2: TEST CASES AND OPERATING CONDITIONS AT $20^{\circ} \mathrm{C}$

\begin{tabular}{|c|c|c|c|c|c|c|}
\hline Fluid & Acronym & $\begin{array}{c}u_{g} \\
\mathrm{~ms}^{-1}\end{array}$ & $\begin{array}{c}p \\
\text { bar }\end{array}$ & $\begin{array}{c}G L R \\
-\end{array}$ & $\begin{array}{l}M \\
-\end{array}$ & $\begin{array}{c}\text { We } \\
-\end{array}$ \\
\hline \multirow{4}{*}{ A } & A 1.1 & \multirow{4}{*}{58} & 1 & 0.39 & 4 & 120 \\
\hline & A 1.2 & & 2 & 0.78 & 9 & 240 \\
\hline & A 1.3 & & 7 & 2.75 & 31 & 839 \\
\hline & A 1.4 & & 11 & 4.32 & 48 & 1318 \\
\hline \multirow{4}{*}{ A } & A 2.1 & \multirow{4}{*}{74} & 1 & 0.39 & 7 & 196 \\
\hline & A 2.2 & & 2 & 0.78 & 15 & 393 \\
\hline & A 2.3 & & 7 & 2.75 & 51 & 1374 \\
\hline & A 2.4 & & 11 & 4.32 & 80 & 2160 \\
\hline \multirow{4}{*}{ B } & B1.1 & \multirow{4}{*}{58} & 1 & 0.39 & 4 & 121 \\
\hline & B1.2 & & 2 & 0.78 & 9 & 242 \\
\hline & B1.3 & & 7 & 2.75 & 30 & 848 \\
\hline & B1.4 & & 11 & 4.32 & 48 & 1332 \\
\hline \multirow{4}{*}{ B } & B2.1 & \multirow{4}{*}{74} & 1 & 0.39 & 7 & 198 \\
\hline & B 2.2 & & 2 & 0.78 & 14 & 397 \\
\hline & B2.3 & & 7 & 2.75 & 50 & 1389 \\
\hline & B2.4 & & 11 & 4.32 & 79 & 2183 \\
\hline
\end{tabular}

at least $50 \mathrm{~ms}$, which ensures an acceptable statistic convergence as at least 50 convective times are captured. The time stepping during a simulation is limited by the $C F L$-number to be smaller than 0.4 and results in time steps of approximately $0.25 \mu \mathrm{s}$. The simulated time span is then evaluated at $0.1 \mathrm{~ms}$, which is 400 times bigger than the computational time step of the simulation and makes frequency analysis possible in the range of $20 \mathrm{~Hz}$ to $5000 \mathrm{~Hz}$.

Simulations of Newtonian fluids at ambient pressure have already been validated with experiments with regard to morphology of the primary breakup and quantitative analysis of breakup frequency and length in previous investigations [20,21]. Detailed information on the definitions of the breakup length and the breakup frequency as well as their determination can be found in [20].

\section{Influence of pressure on breakup morphology}

Figure 4depicts snapshots of the liquid jet of the cases A1.1 to A1.4 from experiment and simulation. The left part shows a high-speed image from the experiment, whereas the image in the middle and on the right shows projections of the three di- 


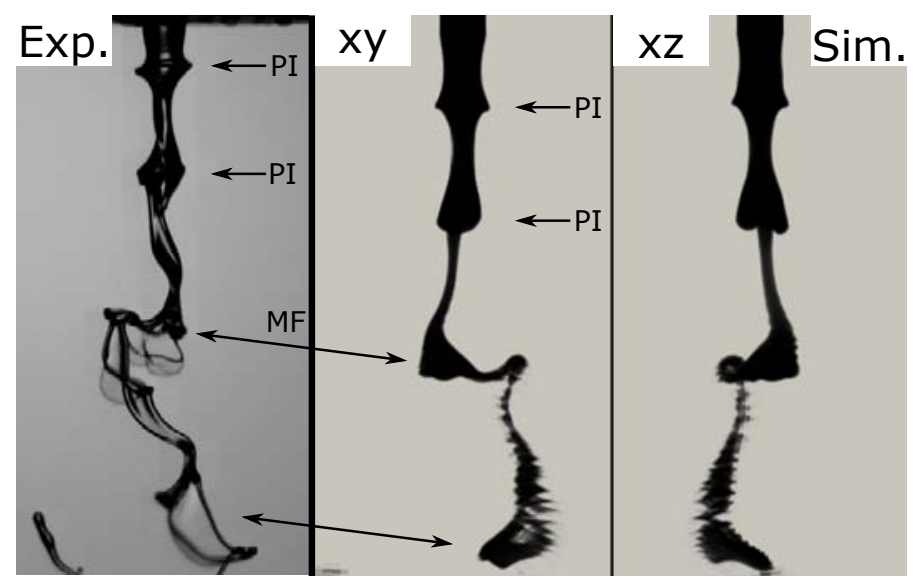

(a) CASE A1.1: $p=1$ bar

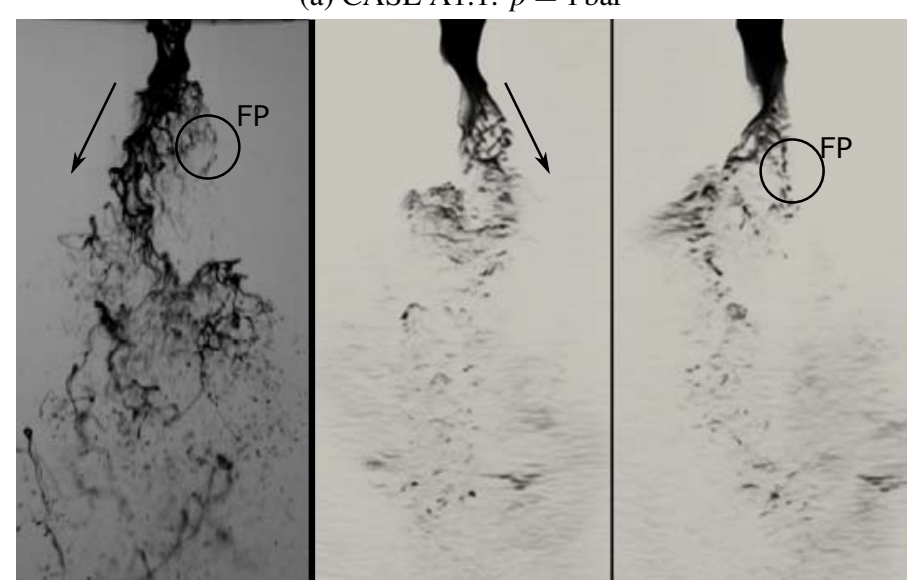

(c) CASE A1.3: $p=7$ bar

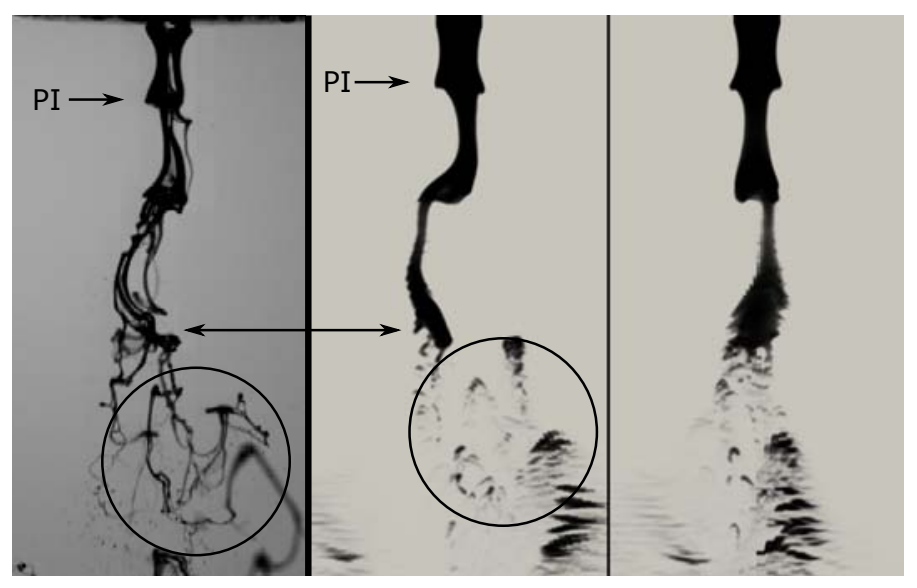

(b) CASE A1.2: $p=2$ bar

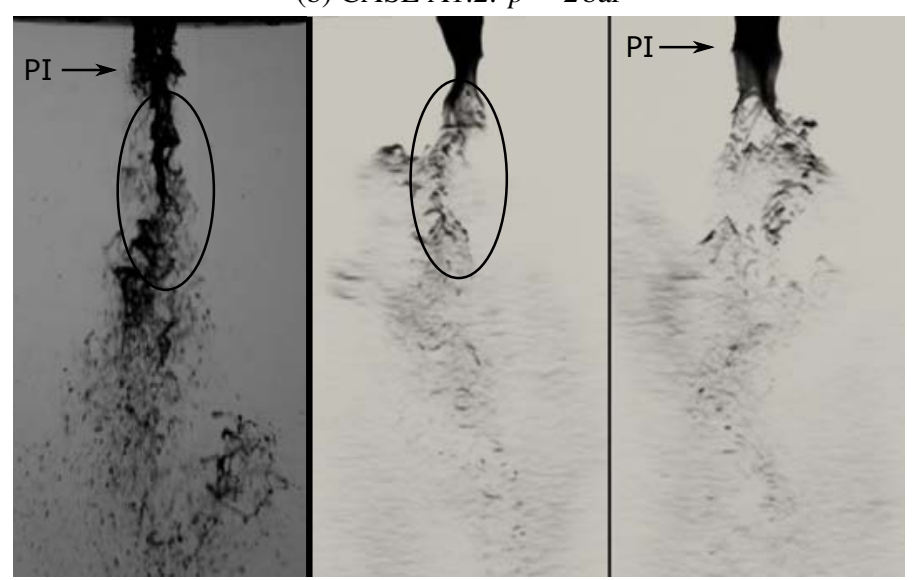

(d) CASE A1.4: $p=11 \mathrm{bar}$

FIGURE 4: INFLUENCE OF PRESSURE ON BREAKUP MORPHOLOGY: FLUID A ( $\mu=100 \mathrm{mPas}, u_{g}=58 \mathrm{~m} \mathrm{~s}^{-1}$ )

mensional liquid structure from the simulation to the $\mathrm{xy}-$ and $\mathrm{xz}-$ plane, respectively (see also Fig. 4a, the other figures are analogously organized). Each snapshot shows a domain of approx. $12 \mathrm{~mm}$ in width and $22 \mathrm{~mm}$ length.

Comparison shows, that the breakup morphology is in general well captured by the simulation. Comparing case A1.1 in Fig. 4a experiment and simulation both show the same pulsating mode as primary instability (marked by horizontal arrows annotated with PI (pulsating instability)) with the same wave length and amplitude. Moreover, they both show the same features and characteristic length scales (emphasized by double arrows). In the experiment, the jet breakup follows the membrane type regime with the characteristic formation and disintegration of thin membranes (see bottom of Fig. 4a marked with MF (membrane formation)). The formation of theses membranes is well captured by the simulation, although the grid resolution of $50 \mu \mathrm{m}$ is not sufficient to reproduce the membrane itself, as their thick- ness is well below a tenth of the grid resolution.

By increasing the reactor pressure at otherwise constant operating conditions the liquid jet disintegration is amplified. In Fig. $4 \mathrm{~b}$ the jet structure at 2 bar is shown. The ligaments, which separate from the jet structure, are thinner (emphasized by a circle) and the jet surface itself is more perturbed. The primary instability still follows the axis-symmetric pulsating mode, which is also predicted by the simulation. The main breakup mechanism still is the formation of thin membranes, which are characteristic for the membrane type regime.

A further increase of the reactor pressure leads to a fast disintegration of the compact liquid jet structure, as the breakup regime changes from the membrane type to the fiber type, which can be seen in Fig. 4c. In this regime small fibers are peeled off the jet structure, which is predicted by the simulation (marked by a circle, annotated with FP (fiber peel off)). Moreover, the simulation shows the same length scale of the intact liquid structure 
as well as the same radial deflection of the jet (emphasized by arrows).

At 11 bar, the shearing of the jet is even stronger and shortly after the nozzle exit the first fibers are peeled-off. In this context even the protruding part of the axis-symmetric wave (marked by an arrow) disintegrates into fibers, which is to some extent also predicted by the simulation. Moreover, the jet disintegrates into a dense spray region (emphasized by a circle), which also happens in the simulations.

Analogous to Fig. 4, the breakup morphology of fluid A for a gas velocity of $74 \mathrm{~m} \mathrm{~s}^{-1}$ at pressures of 1 bar, 2 bar, 7 bar and 11 bar is shown in Fig. 5. Again, the comparison between experiment and simulation shows good agreement with regard to the breakup regime: For example, membrane type at 1 bar, fiber type at 7 bar and 11 bar and a transition between both at 2 bar. Moreover, the pulsating primary instability mode is correctly predicted.

In comparison to case $\mathrm{A} 1$, the increase of the gas velocity leads to a earlier transition from the membrane to the fiber type. Additionally, for reactor pressures of 1 bar and 2 bar the liquid core structure is significantly shorter than case A1, whereas at 7 bar and 11 bar the differences in the length of the liquid core is negligible. Nevertheless, the increase of gas velocity leads to a stronger disintegration of the jet in terms of smaller ligaments.

Deducing from this qualitative comparison of case A1.1 to A1.4 as well as A2.1 to A2.4 with experiments the following simulations at other operating conditions, thus, are reasonably justified. Additionally, the quantitative analysis of case A1.1 in terms of the breakup frequency $f_{b}$ and breakup length $L_{b}$ is shown in more details in the following sections.

In Fig. 6 the result of the simulations of fluid $B$ for a gas velocity of $58 \mathrm{~m} \mathrm{~s}^{-1}$ at pressures of 1 bar, 2 bar and 11 bar is depicted in terms of the breakup morphology. Case B1.3 (7 bar) is omitted as it is similar to case B1.4.

In contrast to fluid $\mathrm{A}$, the primary instability mode changed from pulsating to flapping (marked by arrowsannotated with FI (flapping instability)). Moreover, the transition between membrane and fiber type breakup is not yet reached, although the size of the membranes as well as the length of the liquid core decreases with rising reactor pressure. Additionally, the length of the liquid core for fluid B is smaller than fluid A for the same operating pressure and gas velocity.

The breakup morphology of case B2.1, B2.2 and B2.4 are shown in Fig. 7 (Once more, case B2.3 is omitted, as the morphology is similiar to B2.4). Again, the results of the simulations are shown. The dominating breakup regime is still the membrane type. Moreover, the primary instability mode is flapping. In comparison to the cases B1, the increase of the gas velocity again leads to a decrease of the size of the liquid structures, which is similar to effect for fluid A.

Overall, an increase of the reactor pressure causes a decrease of size of liquid structures for all cases. Moreover, for fluid A a transition from the membrane to the fiber type regime takes place, whereas for fluid B this point is not yet reached due to the dampening properties of the higher viscosity. In addition, the flapping instability is dominant for fluid B.

\section{Influence of pressure on breakup length}

In Fig. 8 the temporal evolution of the breakup length $L_{b}$ is shown for the simulation of case A1.1. Over the entire period of the simulation, the breakup length displays a periodic behaviour and approximately the same mean breakup length of $15.95 \mathrm{~mm}$, which is in good agreement with the experimental result of $17.62 \mathrm{~mm}$. Moreover, the amplitude of the fluctuation is approx. $4 \mathrm{~mm}$.

The breakup length $L_{b}$ of liquid jets is commonly studied in literature and most correlations account the biggest influence to the momentum flux ratio $M$ and follow the relation $L_{b} \propto M^{-a}$. [6] uses $a=0.5$ and [10] gives $a=0.3$, but the experiments these correlations are based upon, were all conducted at ambient pressure.

Instead, Fig. 9 shows the results of the breakup length analysis for all cases as a function of the reactor pressure. In addition, a fitting curve for each series of the form $L_{b}=C \cdot p^{-a}$ is plotted (the acronym A1 corresponds to the cases A1.1, A1.2, A1.3 and A1.4; A2, B1 and B2 are analogously composed), where $C$ and $a$ are fitting coefficients and $p$ is the reactor pressure.

Comparison shows, that all cases follow the same decrease of the breakup length with increasing reactor pressure. Moreover, the fitting curve represents this behaviour well. The coefficients for each curve are given in Tab. 3 . Due to the chosen set of operating conditions, the momentum flux ratio for each of the series is only a function of the gas density $\rho_{g}$ and therefore of the reactor pressure $p$, as gas $U_{g}$ and liquid velocity $U_{l}$ as well as the liquid density $\rho_{l}$ were kept constant. Comparison with the correlations from literature show, that the exponents are in the same order of magnitude, but the influence of liquid viscosity has additionally to be taken into account, as the coefficients for fluid A are roughly two times those of fluid B.

TABLE 3: COEFFICIENTS OF THE FIT FUNCTION

\begin{tabular}{lcccc}
\hline Series & A1 & A2 & B1 & B2 \\
\hline$a$ & 0.49 & 0.44 & 0.23 & 0.20 \\
$C$ & 16.02 & 11.29 & 9.33 & 7.66 \\
\hline
\end{tabular}

In addition, it is remarkable, that the breakup length of fluid B is smaller than the one of fluid A at low reactor pressures, although the liquid viscosity of fluid B is four times higher 


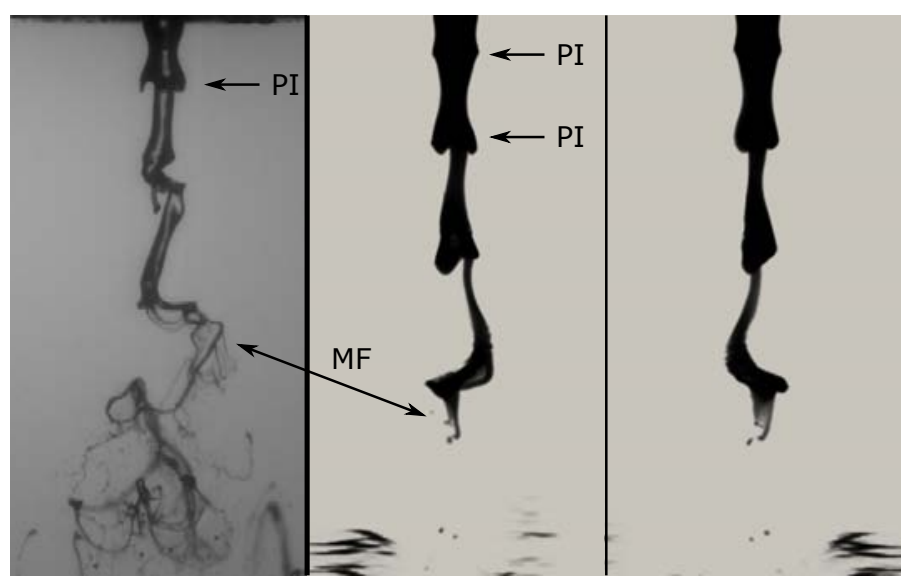

(a) CASE A2.1: $p=1$ bar
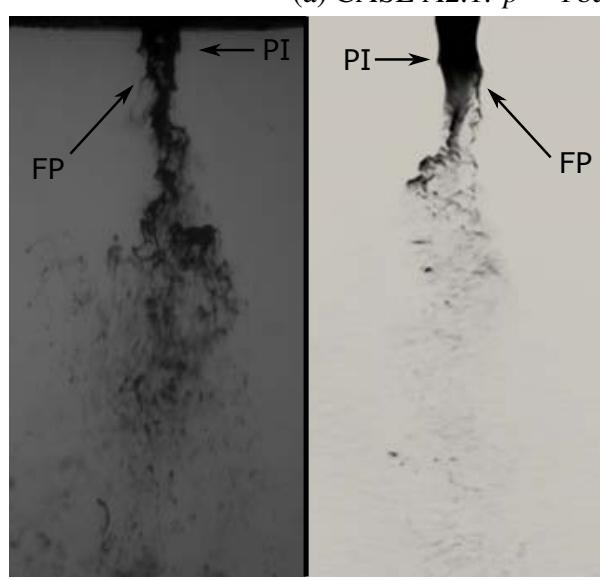

(c) CASE A2.3: $p=7 \mathrm{bar}$

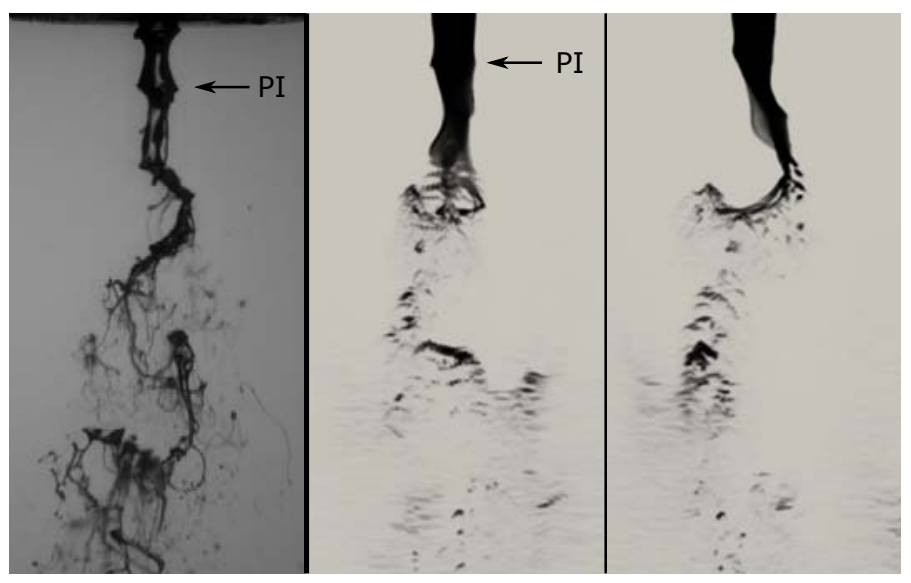

(b) CASE A2.2: $p=2$ bar

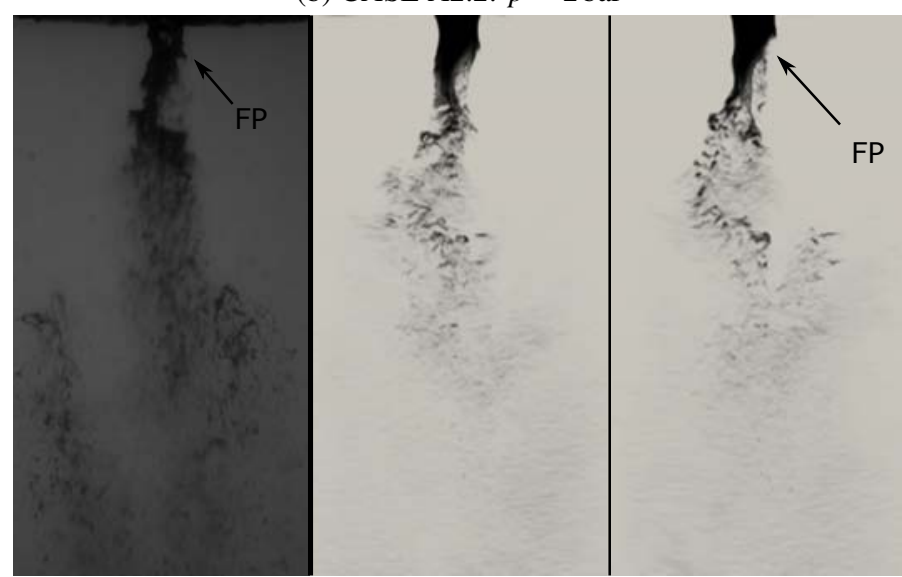

(d) CASE A2.4: $p=11 \mathrm{bar}$

FIGURE 5: INFLUENCE OF PRESSURE ON BREAKUP MORPHOLOGY: FLUID A ( $\mu=100 \mathrm{mPas}, u_{g}=74 \mathrm{~m} \mathrm{~s}^{-1}$ )

than the one of fluid A (see also Tab. 1). This is can be explained by the two different primary instability modes: Fluid A disintegrates with a pulsating primary instability, whereas fluid B shows a flapping primary instability at low reactor pressures(see also Fig. 4a and Fig. 6a).

This finding also is in accordance with a previous investigations [22], wherein a change of the primary instability mode was induced by a slight change of the nozzle geometry at constant operating conditions and a decrease in the liquid breakup length by a change from the pulsating to the flapping mode was reported.

\section{Influence of reactor pressure upon the breakup fre- quency}

Furthermore, the influence of reactor pressure upon the jet breakup is quantitatively investigated in terms of the breakup frequency $f_{b}$, which is defined as the passing frequency of the axis-symmetric wave in case of the pulsating mode.
Figure 10 exemplarily depicts the monitored signal of three virtual probes (top) of case A1.1 quantifying the liquid presence and the energy spectrum from a Fast Fourier transformation of these signals. The analysis yields a frequency of $537 \mathrm{~Hz}$, which is slightly higher than the measured value of $480 \mathrm{~Hz}$. Additionally, there is a good agreement between this frequency with the fundamental mode of the liquid breakup length signal, which was determined to $533 \mathrm{~Hz}$.

The temporal behaviour of the jet breakup is also studied in terms of the breakup frequency $f_{b}$ for the other cases of fluid A. Figure 11 depicts the result of this analysis by means of the breakup frequency as a function of the reactor pressure. In addition, the available experimental data is also plotted. The agreement between experiments and simulations is good with regard to the absolute values as well as the qualitative trend.

Moreover, the simulations show a decreasing influence on of the breakup frequency with higher reactor pressures and it seems 


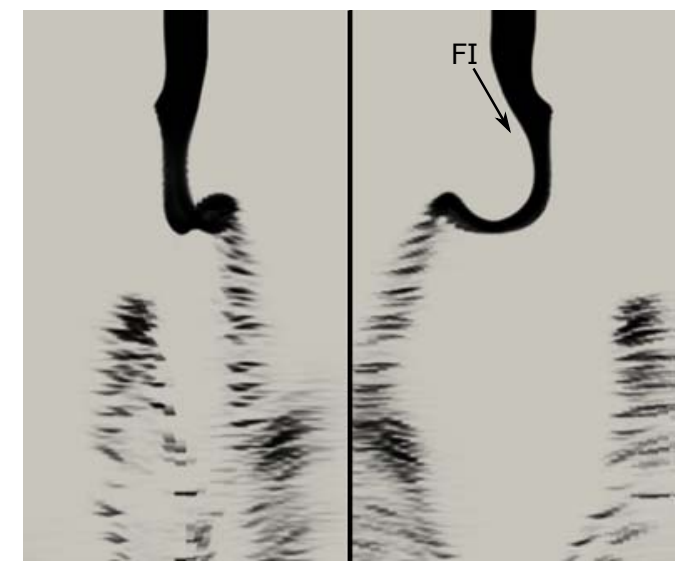

(a) CASE B1.1: $p=1$ bar

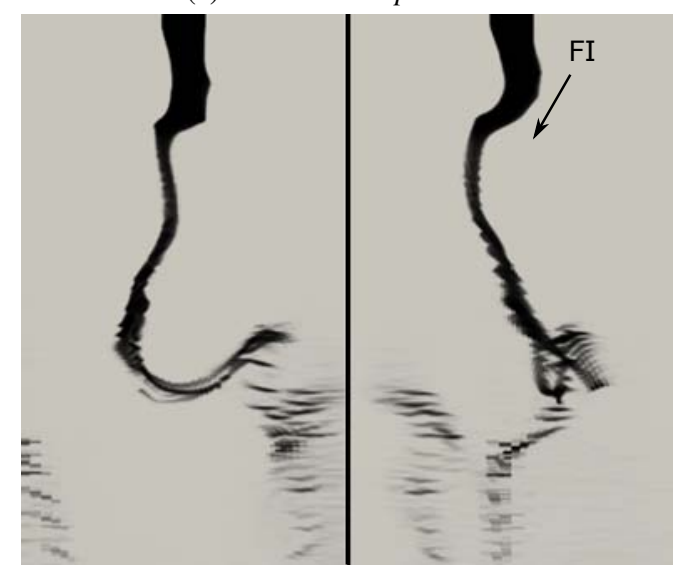

(b) CASE B1.2: $p=2$ bar

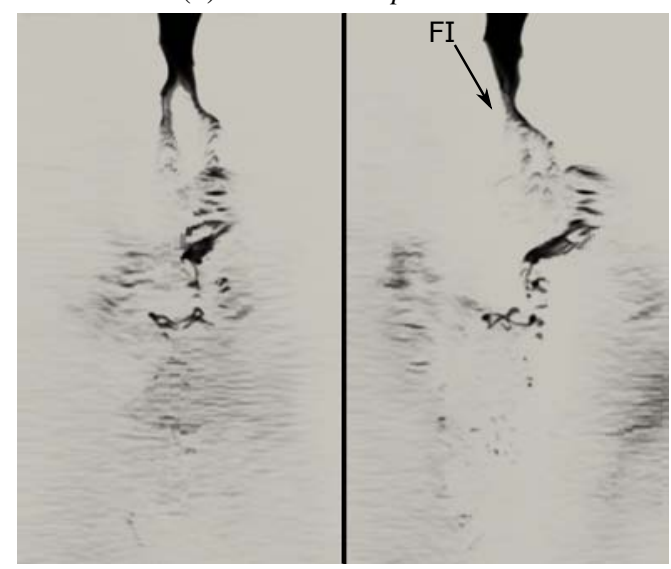

(c) CASE B1.3: $p=11$ bar

FIGURE 6: INFLUENCE OF PRESSURE ON BREAKUP MORPHOLOGY: FLUID B ( $\left.\mu=400 \mathrm{mPas}, u_{g}=58 \mathrm{~m} \mathrm{~s}^{-1}\right)$

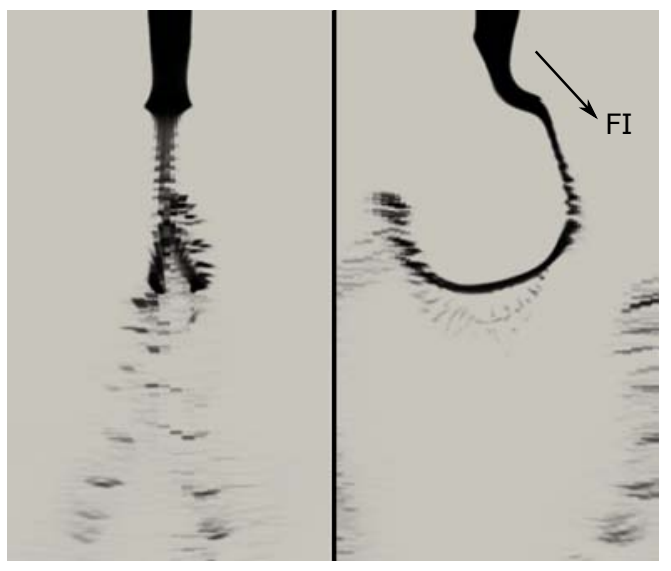

(a) CASE B1.1: $p=1$ bar

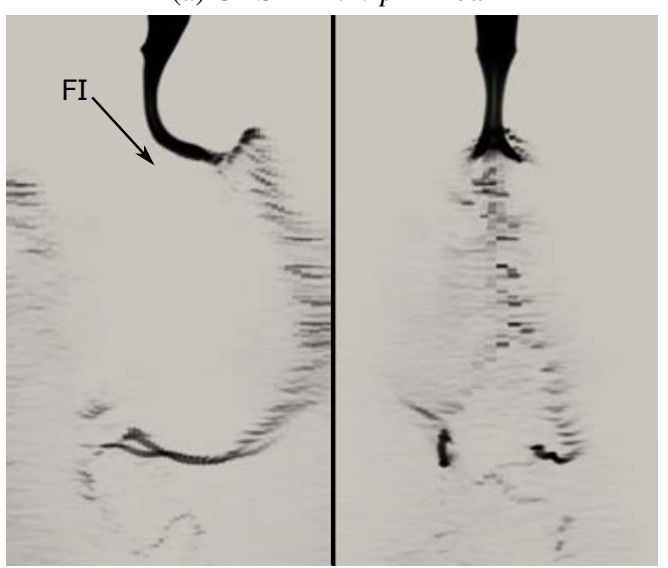

(b) CASE B1.2: $p=2$ bar

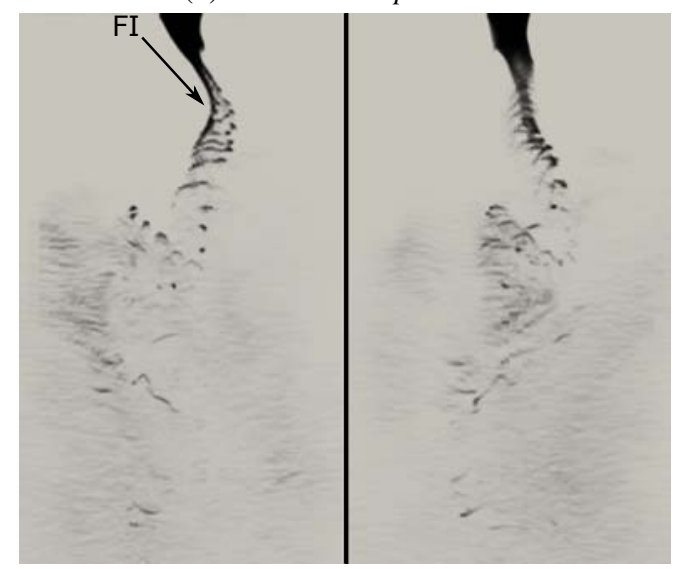

(c) CASE B1.3: $p=11$ bar

FIGURE 7: INFLUENCE OF PRESSURE ON BREAKUP MORPHOLOGY: FLUID B ( $\left.\mu=400 \mathrm{mPas}, u_{g}=74 \mathrm{~m} \mathrm{~s}^{-1}\right)$ 


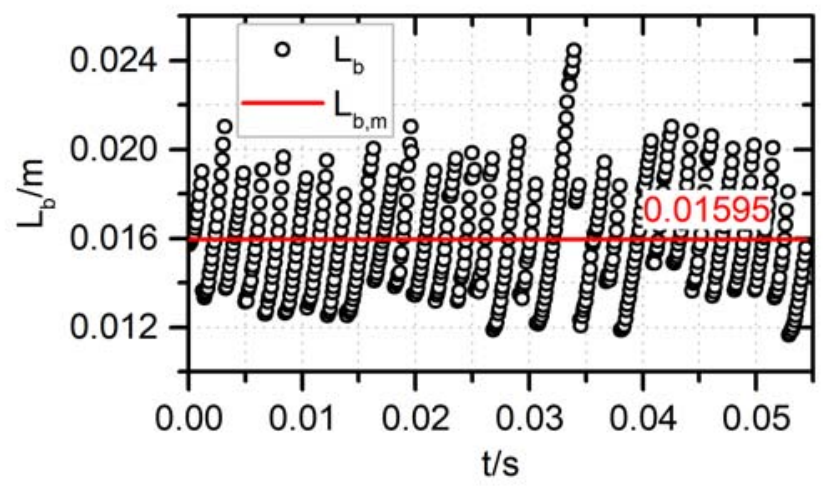

FIGURE 8: BREAKUP LENGTH $L_{b}$ VS. TIME $t$ (CASE A1.1)

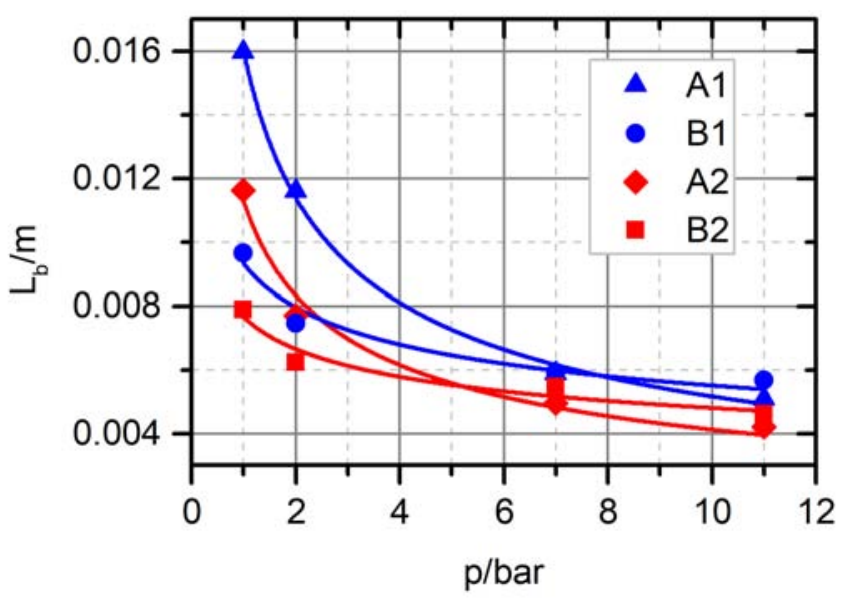

FIGURE 9: BREAKUP LENGTH $L_{b}$ VS. PRESSURE $p$

that, with rising pressure a saturation is reached, for which a further increase of the reactor pressure does not provoke a rise of the breakup frequency any more. This saturation is already reached in case of A1, whereas in case of A2 the breakup frequency still increases with rising reactor pressure.

In Fig. 12 the determined breakup frequencies for fluid B are shown. Again, the qualitative agreement between experiment and simulation is good, although the absolute values are underestimated by approx. $200 \mathrm{~Hz}$ in the simulations. Moreover, in comparison to fluid A the saturation point is not yet reached, but for cases B1 the influence of the pressure on the breakup frequency is already declining.

\section{CONCLUSION AND OUTLOOK}

EFG for non-conventional fuels are typically operated at elevated reactor pressure to increase the overall efficiency of the
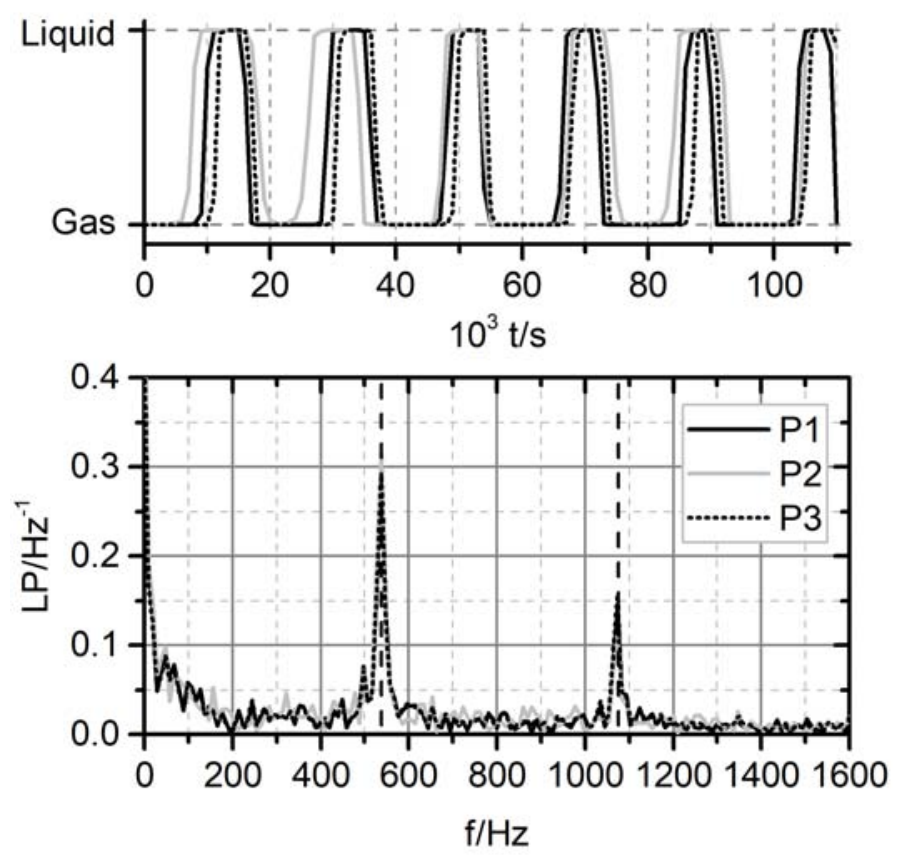

FIGURE 10: DETERMINATION OF THE BREAKUP FREQUENCY: LIQUID PRESENCE VS. TIME $t$ AT THREE VIRTUAL PROBES (TOP) AND LIQUID PRESENCE SPECTRUM $L P$ VS. FREQUENCY $f$ OF CASE A1.1. THE VERTICAL LINES MARK THE FUNDAMENTAL MODE AND ITS FIRST HARMONIC

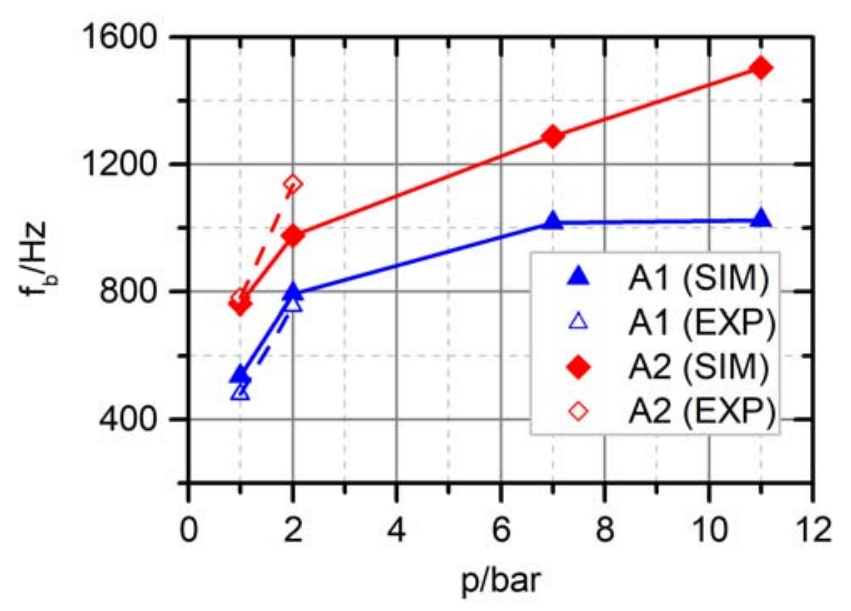

FIGURE 11: BREAKUP FREQUENCY $f_{b}$ VS. PRESSURE $p$ : FLUID A $(\mu=100 \mathrm{mPas})$ 


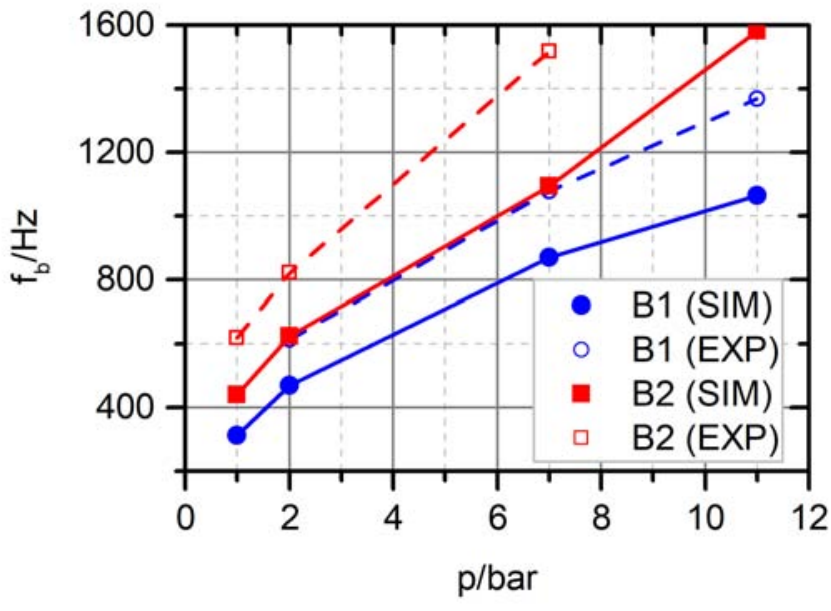

FIGURE 12: BREAKUP FREQUENCY $f_{b}$ VS. PRESSURE $p$ : FLUID B $(\mu=400 \mathrm{mPas})$

process, therefore rendering an understanding of the physics of the jet breakup of high-viscosity fuels and especially the influence of reactor pressure upon it mandatory.

The influence of reactor pressure upon the primary breakup was studied by numerical simulations, which were validated with experimental data. By an extensive comparison of experimental data and simulations in terms of the breakup morphology for the cases A1.1 to A1.4 as well as A2.1 to A2.4 the general applicability of the VOF-method for the jet breakup at different reactor pressures was proven. The analysis showed very good agreement between measurement and simulation with regard to the morphology, the primary instability mode as well as characteristic structures of the jet breakup. In addition, the quantitative analysis of case A1.1 showed very good agreement between measurement and simulation with regard to the breakup frequency and length.

In general, the influence of reactor pressure upon the breakup morphology with rising pressure is summarized as follows: (I) the breakup regime changes from membrane to fiber type, (II) the disturbances of the jet surface increase and the jet disintegration intensifies, (III) the length sclae of the liquid structures decreases.

The analysis of the breakup length showed, that the influence of reactor pressure can be described in terms of the momentum flux ratio. The derived correlation follows the form of the one commonly used for low-viscosity liquids: $L_{b} \propto M^{-a}$ with $a \in[0.2 ; 0.5]$. But in the case of high-viscosity liquids one additional parameter has to be taken into account: the mode of the primary instability (pulsating or flapping).

Analysis of the breakup frequency showed very good agreement with the experimental data for fluid A and a declining influence of increasing the reactor pressure upon the breakup fre- quency to the point, where a saturation was reached. For fluid B, the analysis yielded reasonable agreement between experiments and simulations and showed the same saturation behaviour.

In order to better understand the atomisation behaviour of high-viscosity fuels in twin-fluid nozzles further experimental and numerical work is ongoing, especially with regard to the influence of rheology of non-Newtonian liquids, nozzle design and scalability as well as to the influence of the primary instability upon the morphology and local stoichiometry.

\section{ACKNOWLEDGMENT}

The authors acknowledge support by the state of BadenWürttemberg through bwHPC. Additionally, the authors like to thank the Helmholtz Association of German Research Centres (HGF) for funding.

\section{REFERENCES}

[1] Higman, C., and Burgt, M. v. d., 2008. Gasification, 2nd ed. ed. Gulf Professional Pub./Elsevier Science, Amsterdam and Boston.

[2] Jakobs, T., Djordjevic, N., Fleck, S., Mancini, M., Weber, R., and Kolb, T., 2012. "Gasification of high viscous slurry $\mathrm{R} \& \mathrm{D}$ on atomization and numerical simulation". Applied Energy, 93, pp. 449-456.

[3] Dumouchel, C., 2008. "On the experimental investigation on primary atomization of liquid streams". Experiments in Fluids, 45(3), pp. 371-422.

[4] Farago, Z., and Chigier, N., Monday 11 June 1990. "Parametric Experiments on Coaxial Airblast Jet Atomization". In ASME 1990 International Gas Turbine and Aeroengine Congress and Exposition, p. V003T06A016.

[5] Chigier, N., and Farago, Z., 1992. "Morphological Classification of Disintegration of Round Liquid Jets in a Coaxial Air Stream". Atomization and Sprays, 2(2), pp. 137-153.

[6] Lasheras, J. C., Villermaux, E., and Hopfinger, E. J., 1998. "Break-up and atomization of a round water jet by a high-speed annular air jet". Journal of Fluid Mechanics, 357(357), pp. 351-379.

[7] Lasheras, J. C., and Hopfinger, E. J., 2000. "Liquid Jet Instability and Atomization in a Coaxial Gas Stream". Annual Review of Fluid Mechanics, 32(1), pp. 275-308.

[8] Marmottant, P., and Villermaux, E., 2004. "On spray formation”. Journal of Fluid Mechanics, 498, pp. 73-111.

[9] Eroglu, H., Chigier, N., and Farago, Z., 1991. "Coaxial atomizer liquid intact lengths". Physics of Fluids A: Fluid Dynamics, 3(2), p. 303.

[10] Leroux, B., Delabroy, O., and Lacas, F., 2007. "Experimentel Study of Coaxial Atomizers Scaling. Part I: Dense Core Zone". Atomization and Sprays, 17(5), pp. 381-407. 
[11] Leroux, B., Delabroy, O., and Lacas, F., 2007. "Experimentel Study of Coaxial Atomizers Scaling. Part II: Diluted Zone". Atomization and Sprays, 17(5), pp. 409-430.

[12] Tian, X.-S., Zhao, H., Liu, H.-F., Li, W.-F., and Xu, J.-L., 2014. "Effect of central tube thickness on wave frequency of coaxial liquid jet”. Fuel Processing Technology, 119, pp. 190-197.

[13] Jakobs, T., Djordjevic, N., Sanger, A., Zarzalis, N., and Kolb, T., 2015. "Influence of Reactor Pressure on Twinfluid Atomization: Basic Inverstigation on Burner Design for High-Pressure Entrained Flow Gasifier". Atomization and Sprays, 25(12), pp. 1081-1105.

[14] Zhao, H., Liu, H.-F., Xu, J.-L., Li, W.-F., and Cheng, W., 2012. "Breakup and atomization of a round coal water slurry jet by an annular air jet". Chemical Engineering Science, 78(0), pp. 63-74.

[15] Tian, X.-S., Zhao, H., Liu, H.-F., Li, W.-F., and Xu, J.-L., 2015. "Three-dimensional large eddy simulation of round liquid jet primary breakup in coaxial gas flow using the VOF method". Fuel Processing Technology, 131, pp. 396402.

[16] Gorokhovski, M., and Herrmann, M., 2008. "Modeling Primary Atomization". Annual Review of Fluid Mechanics, 40(1), pp. 343-366.

[17] Sänger, A., Jakobs, T., Djordjevic, N., and Kolb, T., 2014. "Effect of primary instability of a high viscous liquid jet on the spray quality generated by a twin-fluid atomizer". In Proceedings 26th European Conference on Liquid Atomization \& Spray Systems, L. Achelis and U. Fritsching, eds.

[18] Sänger, A., Jakobs, T., Djordjevic, N., and Kolb, T., 2015. "Experimental investigation on the influence of ambient pressure on twin-fluid atomization of liquids with various viscosities". In Proceedings 13th International Conference on Liquid Atomization \& Spray Systems.

[19] Jampolski, L., Sänger, A., Jakobs, T., Guthausen, G., Kolb, T., and Willenbacher, N., 2016. "Improving the processability of coke water slurries for entrained flow gasification". Fuel, 185, pp. 102-111.

[20] Müller, T., Sänger, A., Habisreuther, P., Jakobs, T., Trimis, D., Kolb, T., and Zarzalis, N., 2016. "Simulation of the primary breakup of a high-viscosity liquid jet by a coaxial annular gas flow". International Journal of Multiphase Flow, 87, pp. 212-228.

[21] Müller, T., Habisreuther, P., Zarzalis, N., Sänger, A., Jakobs, T., and Kolb, T., 2016. "Investigation on Jet Breakup of High-Viscous Fuels for Entrained Flow Gasification". In ASME Turbo Expo 2016: Turbomachinery Technical Conference and Exposition, p. V003T03A003.

[22] Müller, T., Dullenkopf, A., Habisreuther, P., Zarzalis, N., Sänger, A., Jakobs, T., and Kolb, T., 2017. "Influence of nozzle design upon the primary jet breakup of high- viscosity fuels for entrained flow gasification". In ASME Turbo Expo 2017: Turbomachinery Technical Conference and Exposition, p. V003T03A002.

[23] OpenCFD Ltd., 2015. Openfoam - the open source cfd toolbox, http://www.openfoam.org/docs/.

[24] Hirt, C., and Nichols, B., 1981. "Volume of fluid (VOF) method for the dynamics of free boundaries". Journal of Computational Physics, 39(1), pp. 201-225.

[25] Berberovic, E., 2010. "Investigation of Free-surface Flow Associated with Drop Impact: Numerical Simulations and Theoretical Modeling". Ph.d. thesis, Technische Universität, Darmstadt.

[26] Brackbill, J., Kothe, D., and Zemach, C., 1992. "A continuum method for modeling surface tension". Journal of Computational Physics, 100(2), pp. 335-354.

[27] Weller, H. G., 2008. A new approach to VOF-based interface capturing methods for incompressible and compressible flow. Tech. Rep. TR/HGW/04, OpenCFD Ltd.

[28] Zalesak, S. T., 1979. "Fully multidimensional fluxcorrected transport algorithms for fluids". Journal of Computational Physics, 31(3), pp. 335-362.

[29] Leonard, A., 1975. "Energy Cascade in Large-Eddy Simulations of Turbulent Fluid Flows". In Advances in Geophysics: Turbulent Diffusion in Environmental Pollution, Proceedings of a Symposium held at Charlottesville, F. N. Frenkiel and R. E. Munn, eds., Vol. Volume 18, Part A. Elsevier, pp. 237-248.

[30] Smagorinsky, J., 1963. "General circulation experiments with the primitive equations". Monthly Weather Review, 91(3), pp. 99-164.

[31] Fureby, C., 1996. "On subgrid scale modeling in large eddy simulations of compressible fluid flow". Physics of Fluids, 8(5), p. 1301.

[32] du Noüy, P. L., 1925. "An Interfacial Tensiometer for Universal Use". The Journal of General Physiology, 7, pp. 625-631.

[33] Searle, G. F. G., 1912. "Simple Viscometer for very Viscous Liquids". Proceedings of the Cambridge Philosophical Society, 16, p. 600. 


\section{Repository KITopen}

Dies ist ein Postprint/begutachtetes Manuskript.

Empfohlene Zitierung:

Sänger, A.; Jakobs, T.; Kolb, T.; Müller, T.; Kadel, K.; Habisreuther, P.; Trimis, D.; Zarzalis, $\mathrm{N}$.

Influence of Reactor Pressure on the Primary Jet Breakup of High-Viscosity Fuels: Basic Research for Simulation-Assisted Design of Low-Grade Fuel Burner.

2018. ASME Turbo Expo : Turbomachinery Technical Conference and Exposition (GT), Oslo, Norway, June 11-15, 2018. Vol.: 3

doi:10.5445/IR/1000085900

Zitierung der Originalveröffentlichung:

Sänger, A.; Jakobs, T.; Kolb, T.; Müller, T.; Kadel, K.; Habisreuther, P.; Trimis, D.; Zarzalis, $\mathrm{N}$.

Influence of Reactor Pressure on the Primary Jet Breakup of High-Viscosity Fuels: Basic

Research for Simulation-Assisted Design of Low-Grade Fuel Burner.

2018. ASME Turbo Expo : Turbomachinery Technical Conference and Exposition (GT), Oslo, Norway, June 11-15, 2018. Vol.: 3, Article no: 75950, The American Society of Mechanical Engineers (ASME).

doi:10.1115/GT2018-75950 